\title{
Radiologic Technologist
}

National Cancer Institute

\section{Source}

National Cancer Institute. Radiologic Technologist. NCI Thesaurus. Code C53424.

A person trained and qualified to perform radiographic procedures by the application of ionizing radiation to produce images on film and on computer assisted equipment displays and perform other related duties including but not limited to the patient instruction on a radiographic procedure, patient positioning, immobilization, protection, and observation during the procedure; radiographs generation and images records maintenance; equipment operation, minor adjustments and evaluation for modification or replacement. 